\title{
La motivación de la población infantil para lograr su asistencia a las bibliotecas públicas de la Ciudad de México
}

\section{María de los Ángeles Ciprés Oliva Alva Flores Romero}

Biblioteca del Instituto de Investigaciones Filológicas de la UNAM (México)

\section{Resumen}

Se presenta un diagnóstico realizado en las bibliotecas públicas de la Ciudad de México para conocer la situación de la labor de motivación que se realiza con el fin de lograr la asistencia de la población infantil a ellas. El objetivo específico era presentar las opiniones de los encargados de las bibliotecas públicas acerca de la motivación realizada en sus instituciones, así como las opiniones y sugerencias de los niños. Para ello, se analizó la información contenida en las fuentes biblio-hemerográficas relacionadas con el tema y se recurrió a la observación directa y a la aplicación de cuestionarios a los encargados de las bibliotecas públicas de la Red de Bibliotecas Públicas de la Ciudad de México y a los niños de 5 a 11 años de edad de las 16 delegaciones. El 91,57\% de las bibliotecas encuestadas manifestó realizar alguna labor de motivación. Casi todos los niños han asistido alguna vez a la biblioteca pública y muchos acuden regularmente. Sin embargo, en la mayor parte de las bibliotecas públicas de la Ciudad de México no se realiza una labor de motivación propiamente dicha, encaminada a lograr la asistencia de la población infantil a ellas, y, cuando se realiza, se lleva a cabo de una manera inadecuada.

Palabras clave: Bibliotecas públicas. Bibliotecas infantiles. Estudios de usuarios. Motivación. Niños. Ciudad de México.

\section{Abstract}

A diagnosis of the motivation efforts carried in the public libraries of Mexico City in order to improve the attendance of children is presented. Both the perspectives of librarians and children were researched. For this, bibliohemerographic information, direct observation and questionnaires were used. $91,57 \%$ of the librarians answered that they were carrying out motivation tasks. Almost all the children had attended a public library at least once and many were frequently using it. However, motivation is not well developed in most public

Scire. $13: 1$ (en.-jun. 2007) 87-119. ISSN 1135-3716. 
libraries in Mexico City. Most libraries do not have a motivation programme, and when it is addressed, it is usually inadequate.

Keywords: Public libraries. Children libraries. User studies. Motivation. México City.

\section{Introducción}

Únicamente un pueblo instruido tiene la capacidad necesaria para comprender y valorar su pasado, afrontar y superar los retos presentes y asegurarse un mejor futuro. Sin embargo, países que se encuentran sumidos en profundas (y ya históricas) crisis económicas, políticas o sociales, como es el caso de México, no tienen estas características. Esto se debe principalmente a que estos países presentan también agudas crisis culturales que condicionan por una parte la existencia de una educación formal, entendida como "aquella inscrita en el sistema educativo legalmente establecido" (Diccionario de ciencias de la educación, 1983, p. 191), precaria en calidad y cantidad, y, por otra, la inexistencia de un hábito de aprendizaje autodidacta que permita a la población procurarse por sí misma recursos de educación más allá de los que los centros escolares ofrecen. Como Magaloni (1984, p. 202) mostró en una investigación, en México "no existe una conducta lectora de aproximación espontánea y organizada hacia el conocimiento, aun entre los jóvenes estudiantes".

Dicha situación pone de relieve la necesidad de que otras instituciones sociales complementen la labor que realizan los centros de educación formal y que además permitan el desarrollo de un hábito de aprendizaje autodidacta entre la población. Como expresó la Unesco, "Los estudiantes de todas las edades han de poder contar con la biblioteca pública para complementar los medios que les ofrecen los establecimientos de enseñanza [...] además de atender los requerimientos de quienes practican la autoeducación" (Palacios, 1978, p. 24).

En este punto entra en juego la biblioteca como una institución social sensible a las necesidades de su entorno, participativa con otras instituciones y que responda con su labor a la parte de responsabilidad que tiene en la educación de los ciudadanos. Como tal tiene que recurrir a cualquier herramienta para conseguir la asistencia de todos los usuarios potenciales. Sin embargo, la realidad nos muestra que la biblioteca pública se ha caracterizado por mantener un papel pasivo en espera de la llegada de los usuarios. Esta situación debe cambiar radicalmente, pues la biblioteca pública, para cumplir de una manera más real los objetivos y funciones que se le han asignado, tiene la obligación de realizar una labor de motivación que incremente el interés y la asistencia de toda la población, especialmente de los niños.

Preocupadas por todo este panorama, y reconociendo ante todo la importancia de las bibliotecas públicas en la elevación cultural de un país como complemento 
de la educación recibida en el aula, empezamos a preguntarnos por la mejor manera de cambiar tal imagen y, por tanto, la actitud de los niños hacia ellas. Después de pensar en varias alternativas, entre las que se encontraban las de mejorar las instalaciones y los servicios, consideramos que ninguna de ellas era suficiente por sí sola para conseguir una mayor afluencia de usuarios a las bibliotecas públicas.

Todo lo anterior nos llevó a considerar la motivación como una herramienta que nos permitiría englobar todos los aspectos que influyen en la asistencia de los niños a las bibliotecas, además de detectar aquellas que necesitan mejorar, así como también obtener las sugerencias de los propios niños para sentirse más a gusto dentro de las bibliotecas públicas.

Las dos poblaciones que se estudiaron fueron los encargados de las bibliotecas públicas y los niños. Esto se determinó así porque eran los más directamente implicados en la poca afluencia de usuarios infantiles en las bibliotecas públicas, aunque somos conscientes de que existen otros ámbitos que quedaron sin estudiar (la escuela y la familia). Sin embargo, dada la amplitud de la investigación, resultaba imposible integrarlas, pero confiamos en que posteriormente se realizará algún trabajo que subsane esta carencia y permita obtener una visión más completa para conseguir elevar la asistencia de la población infantil a las bibliotecas públicas en el ámbito nacional.

Cabe mencionar que el trabajo original consistió en cuatro apartados que eran importantes para cumplir con los objetivos de la investigación: la biblioteca pública, la Red Nacional de Bibliotecas Públicas de México, la motivación infantil y los resultados del diagnóstico. Sin embargo, con base en el objetivo de esta comunicación, nos centraremos en los resultados obtenidos.

\section{Metodología}

Para cumplir con el objetivo planteado al inicio de este estudio se consideró apropiado aplicar la metodología que exponemos a continuación. El primer método utilizado fue el análisis de la información contenida en las fuentes bibliohemerográficas relacionadas con los temas biblioteca pública y motivación infantil. Para obtener la información requerida se utilizaron las técnicas de cuestionarios, entrevista y observación, las cuales fueron aplicadas a los niños y a los encargados de las bibliotecas públicas de la Ciudad de México para conocer su punto de vista acerca de la labor de motivación que se realiza en las bibliotecas, de modo que pudiéramos enterarnos de las carencias que existen en la Red de Bibliotecas Públicas de la Ciudad. Para determinar el número de cuestionarios que se habían de aplicar a encargados de bibliotecas y a niños de entre 5 y 11 años, tuvimos que calcular las muestras representativas de 213 bibliotecas públicas y 1095622 niños. La suma total de la muestra estratificada fue de 1265 elementos (178 encargados de bibliotecas y 1087 niños).

Scire. $13: 1$ (en.-jun. 2007) 87-119. ISSN 1135-3716. 
Para la muestra de los encargados de las bibliotecas públicas fue necesario hacer una estratificación proporcional de estas por delegación, pues el número de bibliotecas existentes en cada una de ellas es variable, de tal forma que no es posible que en todas se aplique el mismo número de cuestionarios (tabla I).

\begin{tabular}{|l|c|c|c|}
\hline \multirow{2}{*}{ Delegación } & \multicolumn{1}{c}{ Total de } & Porcentaje & $\begin{array}{c}\text { N. }{ }^{\circ} \text { de bibliotecas } \\
\text { que se han de encuestar }\end{array}$ \\
\hline Álvaro Obregón & 19 & $9 \%$ & 16 \\
\hline Azcapotzalco & 10 & $5 \%$ & 9 \\
\hline Benito Juárez & 8 & $4 \%$ & 7 \\
\hline Coyoacán & 8 & $4 \%$ & 7 \\
\hline Cuajimalpa de Morelos & 11 & $5 \%$ & 9 \\
\hline Cuauhtémoc & 22 & $10 \%$ & 18 \\
\hline Gustavo A. Madero & 17 & $8 \%$ & 14 \\
\hline Iztacalco & 8 & $4 \%$ & 7 \\
\hline Iztapalapa & 21 & $10 \%$ & 18 \\
\hline Magdalena Contreras, La & 5 & $2 \%$ & 3 \\
\hline Miguel Hidalgo & 14 & $6 \%$ & 11 \\
\hline Milpa Alta & 11 & $5 \%$ & 9 \\
\hline Tláhuac & 12 & $6 \%$ & 11 \\
\hline Tlalpan & 12 & $6 \%$ & 11 \\
\hline Venustiano Carranza & 17 & $8 \%$ & 14 \\
\hline Xochimilco & 18 & $8 \%$ & 14 \\
\hline Total & 213 & $100 \%$ & 178 \\
\hline
\end{tabular}

Tabla I. Muestreo de bibliotecas por delegación.

Las bibliotecas fueron elegidas tomando como fuente básica el directorio de bibliotecas del Distrito Federal editado por el Conaculta; de ahí se seleccionaron sistemáticamente las dos primeras enlistadas en cada apartado delegacional, ya que en todos los casos estas son las más importantes. El resto de las bibliotecas se eligieron al azar.

Para la muestra de los niños fue necesario hacer dos estratificaciones: la primera, para dividir el número total de la muestra en todas las delegaciones de manera proporcional; la segunda se realizó dentro de cada delegación para distribuir proporcionalmente los cuestionarios entre los niños de cada edad. Los resultados de la primera estratificación se presentan en la tabla II. Los de la segunda se muestran en el anexo II.

Los niños se eligieron al azar, cuidando de que los entrevistados tuvieran de 5 a 11 años de edad y habitaran en la delegación donde se estaba realizando la encuesta. 


\begin{tabular}{|l|c|c|c|}
\hline \multirow{2}{*}{ Delegación } & \multicolumn{1}{c|}{$\begin{array}{c}\text { Total de niños } \\
\text { de entre 5 y 11 años }\end{array}$} & $\begin{array}{c}\text { Porcentaje } \\
\text { que se han de encuestar }\end{array}$ \\
\hline Álvaro Obregón & 88678 & $8 \%$ & 87 \\
\hline Azcapotzalco & 55211 & $5 \%$ & 54 \\
\hline Benito Juárez & 33583 & $3 \%$ & 33 \\
\hline Coyoacán & 73625 & $7 \%$ & 76 \\
\hline Cuajimalpa de Morelos & 20183 & $2 \%$ & 22 \\
\hline Cuauhtémoc & 61550 & $6 \%$ & 65 \\
\hline Gustavo A. Madero & 161052 & $15 \%$ & 163 \\
\hline Iztacalco & 51607 & $5 \%$ & 54 \\
\hline Iztapalapa & 248275 & $23 \%$ & 250 \\
\hline Magdalena Contreras, La & 28417 & $2 \%$ & 22 \\
\hline Miguel Hidalgo & 38264 & $3 \%$ & 33 \\
\hline Milpa Alta & 12952 & $1 \%$ & 11 \\
\hline Tláhuac & 39255 & $3 \%$ & 33 \\
\hline Tlalpan & 74005 & $7 \%$ & 76 \\
\hline Venustiano Carranza & 60273 & $6 \%$ & 65 \\
\hline Xochimilco & 48692 & $4 \%$ & 43 \\
\hline Total & 1095622 & $100 \%$ & 1087 \\
\hline
\end{tabular}

Tabla II. Resultados de la primera estratificación.

\section{Resultados}

De acuerdo con los cuestionarios-entrevistas aplicados a los encargados de las bibliotecas públicas y a los niños, y con base en la observación realizada, la situación actual de la motivación que se lleva a cabo en las bibliotecas públicas de la Ciudad de México para lograr la asistencia de la población infantil a ellas es la que exponemos a continuación.

\subsection{Encargados de bibliotecas públicas}

\subsubsection{Bibliotecas públicas que realizan una labor de motivación}

Como demuestran las cifras de la gráfica de la figura 1, un 91,57\% de las bibliotecas encuestadas manifestó realizar alguna labor de motivación. Este porcentaje contrasta con la poca afluencia de usuarios observada en la mayor parte de esas bibliotecas, lo cual indica que realmente no existe una labor de motivación como tal, sino que los bibliotecarios consideran como motivación todos los servicios básicos de la biblioteca.

Como puede observarse, el porcentaje de bibliotecas que manifestó no realizar ninguna labor de motivación es mínimo comparado con el anterior. Esto nos

Scire. $13: 1$ (en.-jun. 2007) 87-119. ISSN 1135-3716. 


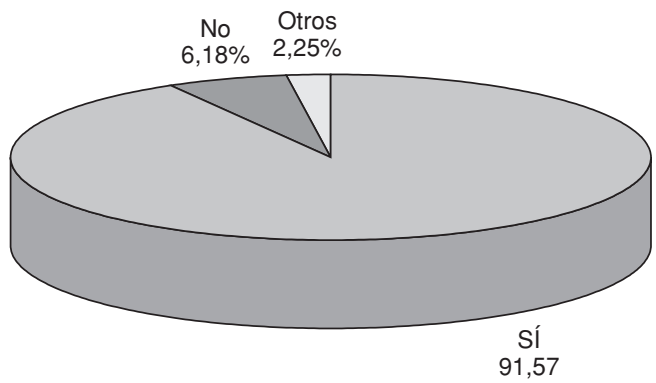

Figura. 1. Bibliotecas públicas que realizan una labor de motivación.

puede dar la idea equivocada de que existen pocas bibliotecas donde no se realiza una labor de motivación, pero en realidad esta cifra debería ser mucho mayor, porque muchas de las que se encuentran en el apartado anterior deberían estar en esta categoría. De todo ello podemos deducir que las bibliotecas que afirmaron no realizar ninguna labor de motivación tienen una idea más clara de lo que es la motivación y, por lo tanto, su respuesta está más cercana a la realidad y es más confiable.

El último porcentaje también representa a aquellas bibliotecas que por razones de fuerza mayor no pudieron ser entrevistadas. Por ejemplo, en la delegación de Milpa Alta existe una biblioteca solo como nombre dado a un espacio, ya que en la práctica es utilizado como bodega. En Tlalpan hay una que no se encuentra abierta en un horario definido, y la mayor parte del tiempo permanece cerrada, según el testimonio de varios vecinos, lo que fue corroborado al acudir varios días y a diferentes horas, sin poder localizar a los encargados. En Xochimilco, una de las bibliotecas que no pudo ser encuestada se encuentra cerrada por falta de personal para atenderla, a pesar de que está instalada y en condiciones de ofrecer servicio al público, mientras que la otra está en proceso de inventario desde hace aproximadamente medio año y todavía no hay fecha de terminación; es importante mencionar que nunca se localizó al personal que se supone debería estar trabajando en el interior de la biblioteca.

\subsubsection{Razones por las que no se realiza una labor de motivación}

Debido a la poca cantidad de bibliotecas que admitieron no realizar ninguna labor de motivación, dentro de la gráfica de la figura 2 existen pocas categorías; de ellas, la de mayor porcentaje es la de "Cercanía con otras instituciones". En esta encontramos aquellas bibliotecas que por estar dentro de una casa de cultura o centro cultural tienen vecindad con instituciones que realizan actividades para niños y madres de familia, actividades que los bibliotecarios consideran más interesantes y atractivas que las que pudieran realizar ellos mismos, por lo que han decidi-

Scire. $13: 1$ (en.-jun. 2007) 87-119. ISSN 1135-3716. 


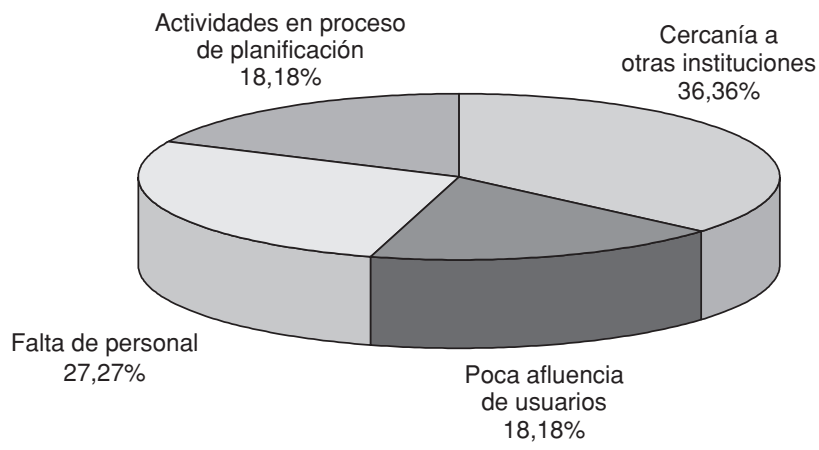

Figura 2. Razones por las que no se realiza una labor de motivación.

do no realizar ninguna. De esta forma, los bibliotecarios han preferido evadir esa responsabilidad y dejársela a otras instituciones. La siguiente categoría es la "Falta de personal"; las bibliotecas que adujeron esta razón son pequeñas y cuentan por lo general con una o dos personas para atenderla. Otras categorías que encontramos en esta gráfica son "Actividades en proceso de planeación" y "Poca afluencia de usuarios".

\subsubsection{Razones por las que se realiza una labor de motivación}

Como puede observarse en la gráfica de la figura 3, la existencia de una labor de motivación de las bibliotecas responde en la mayoría de los casos a una disposición de la DGB de la SEP, y por eso las actividades se realizan meramente para llenar una estadística o informe, pero no se evalúa si dichas actividades se llevan a cabo de una manera adecuada y si realmente motivan la asistencia de los niños a las bibliotecas.

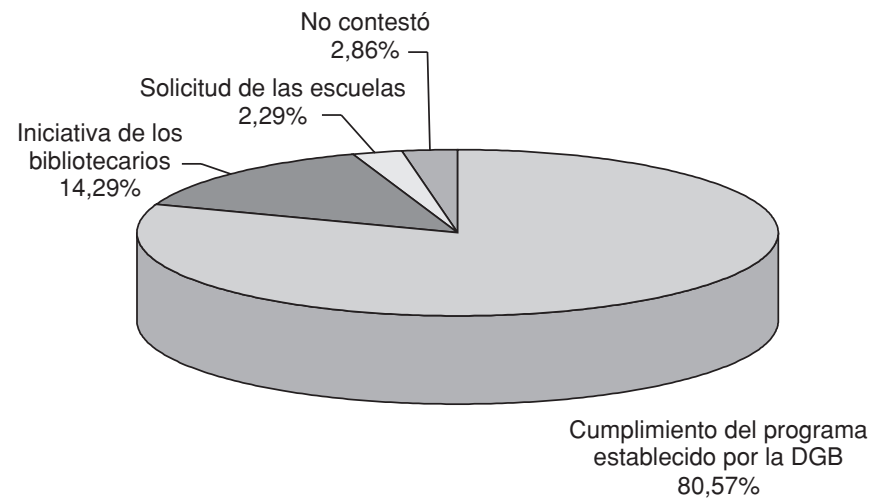

Figura 3. Razones por las que se realiza una labor de motivación.

Scire. $13: 1$ (en.-jun. 2007) 87-119. ISSN 1135-3716. 
Lo anterior es indicador de la falta de interés de los bibliotecarios por sus usuarios, situación que se agrava con la precariedad de recursos que se otorgan a las bibliotecas.

La siguiente categoría, la "Iniciativa de los bibliotecarios", tiene un porcentaje muy bajo. Esto nos demuestra una vez más la falta de iniciativa y creatividad por parte del personal de las bibliotecas, el cual, debido a la relación directa que mantiene con la comunidad podría implementar una mayor cantidad de actividades acordes con las expectativas de sus usuarios reales y potenciales. Las otras categorías que encontramos en esta gráfica son "No contestó" y "Solicitud de las escuelas".

En términos generales, la observación directa nos permitió constatar que la diferencia básica entre las bibliotecas que realizan una buena labor de motivación y las que no consiste en que las primeras tienen al frente a un encargado con interés por sus usuarios y con iniciativa para motivar a su asistencia.

\subsubsection{Evaluación que los bibliotecarios hacen}

de la motivación realizada en sus bibliotecas

La gráfica de la figura 4 nos muestra que la mayoría de los bibliotecarios califican como "Buena" la labor de motivación realizada en sus bibliotecas; sin embargo, la observación directa nos permitió constatar que este resultado no obedece a la realidad de las bibliotecas, sino a una mala interpretación del término labor de motivación por parte de los bibliotecarios, ya que, como se mencionó en la gráfica de la figura 1 , se tiende a considerar como motivación a cualquier servicio que prestan las bibliotecas.

Además, los bibliotecarios se olvidan de tomar en cuenta que quienes realmente califican su trabajo son los niños, y estos, con su inasistencia, reflejan que la motivación no es la adecuada. De acuerdo con lo anterior, podemos afirmar que el porcentaje de bibliotecas que realizan una buena motivación es en realidad menor, pero los bibliotecarios no quisieron admitirlo como tal.

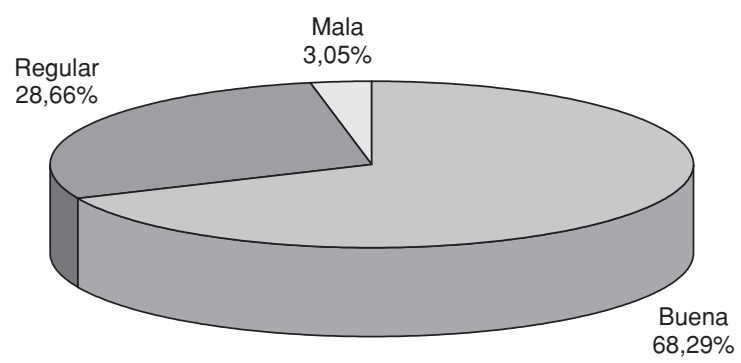

Figura 4. Evaluación que los bibliotecarios hacen de la motivación realizada en sus bibliotecas.

Scire. $13: 1$ (en.-jun. 2007) 87-119. ISSN 1135-3716. 
La siguiente categoría que los bibliotecarios consideraron fue "Regular"; dentro de ella se encuentran los bibliotecarios que tenían mayor conciencia de que su labor de motivación no es lo suficientemente buena para atraer a los niños y contestaron con mayor honestidad que quienes afirmaron realizar una buena labor de motivación.

Podemos decir, entonces, que este porcentaje está más cercano a la realidad que el anterior; sin embargo, consideramos que algunos bibliotecarios que se ubicaron en este rubro en realidad deberían estar en el siguiente.

Por último, un porcentaje pequeño de bibliotecarios admitió que la labor de motivación que realizan es mala. Es notorio el bajo porcentaje que se encuentra en esta categoría, si consideramos la poca afluencia de niños observada en las bibliotecas.

Aun cuando se trata de una respuesta más honesta por parte de los bibliotecarios, quienes reconocen las carencias de sus bibliotecas y aceptan que la motivación realizada en ellas no es la óptima, consideramos que en este rubro el porcentaje debería ser mayor.

En general, podemos decir que a pesar de que los bibliotecarios aceptaron, en mayor o menor grado, ser conscientes de que la labor de motivación que realizan no es la adecuada, no manifestaron mayor preocupación por mejorar tal situación.

\subsubsection{Actividades mediante las que se realiza la labor de motivación}

La "lectura de cuentos" es una de las principales actividades planteadas dentro del programa de fomento a la lectura de la DGB de la SEP, por lo que es la que presenta un mayor porcentaje; sin embargo, a pesar de estar planeada para llevarse a cabo permanentemente, en realidad encontramos que no se realiza de manera adecuada ni en tiempo ni en forma, porque durante el tiempo de las entrevistas

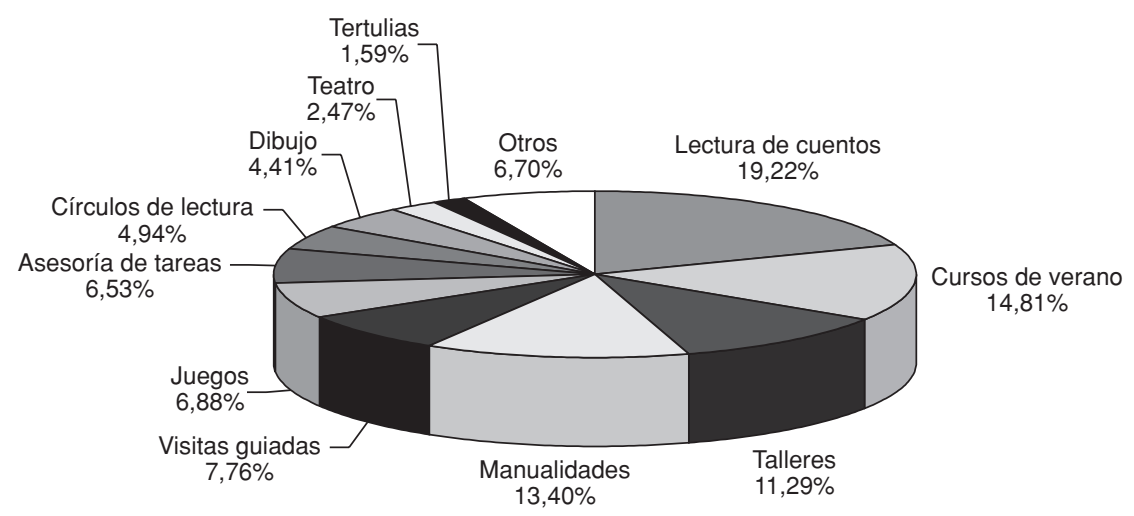

Figura 5. Actividades mediante las que se realiza la labor de motivación.

Scire. $13: 1$ (en.-jun. 2007) 87-119. ISSN 1135-3716. 
nunca se observó la realización de dicha actividad, y en muchas bibliotecas incluso se mencionó que solamente cuando llegaban varios niños se realizaba esta actividad. La aparente falta de interés de los niños por participar en ella podría deberse por una parte a esta misma informalidad en su realización y, por otra, a la falta de entusiasmo de muchos de los bibliotecarios encargados de realizarla. Las otras categorías de esta gráfica son "Cursos de verano", "Talleres", "Manualidades", "Visitas guiadas", "Juegos", "Asesoría de tareas", "Círculos de lectura", "Dibujo", "Teatro" y "Otros".

Como puede observarse, las actividades encontradas en esta gráfica están establecidas en el programa de la DGB de la SEP, lo cual nos muestra la falta de iniciativa y creatividad del personal que trabaja en la mayoría de las bibliotecas públicas.

\subsubsection{Recursos documentales y materiales para niños con los que cuentan las bibliotecas públicas}

Como puede verse en la figura 6 , todas las bibliotecas cuentan con libros para niños, lo cual indica que estos materiales siguen constituyendo la base de los recursos documentales que se ofrecen a los usuarios infantiles.

La observación directa nos permitió constatar que en la mayoría de los casos los libros con los que cuentan las bibliotecas son insuficientes para satisfacer las necesidades de sus usuarios. Por lo que respecta al contenido de los libros, se da prioridad a los textos escolares y se dejan en segundo término los libros de esparcimiento, los cuales resultan muy atractivos y son muy solicitados por los niños.

En cuanto a las revistas, las cifras indican que solo una tercera parte de las bibliotecas cuentan con ellas, y observamos que en su mayoría no están actualizadas. Esto se debe, según el testimonio de los bibliotecarios, al alto costo que implica adquirir este tipo de material. Consideramos que es preocupante que la mayoría de las bibliotecas no cuenten con revistas, ya que por su naturaleza podrían proporcionar información más actualizada y complementar el contenido de los libros.

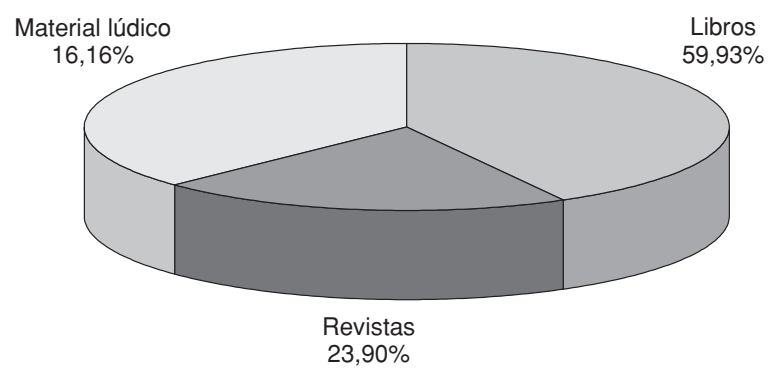

Figura 6. Recursos documentales y materiales para niños con los que cuentan las bibliotecas públicas.

Scire. $13: 1$ (en.-jun. 2007) 87-119. ISSN 1135-3716. 
En situación similar a la de las revistas se encuentra el material lúdico, ya que menos de la tercera parte de las bibliotecas cuentan con este tipo de recursos. Los bibliotecarios comentaron que la razón es que hace tiempo que la DGB de la SEP no les proporciona este material. En nuestra opinión esta situación es grave, ya que se está dejando a las bibliotecas públicas sin uno de los recursos más atractivos y motivadores para los usuarios infantiles.

\subsubsection{Bibliotecas públicas que cuentan con personal} capacitado para atender a usuarios infantiles

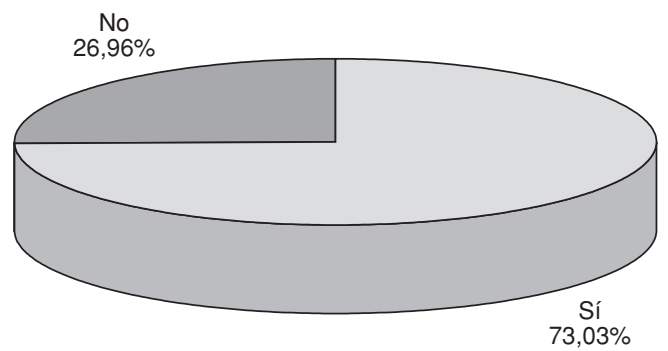

Figura 7. Bibliotecas públicas que cuentan con personal capacitado para atender a usuarios infantiles.

Como muestran las cifras de la gráfica de la figura 7, la gran mayoría de los bibliotecarios entrevistados consideraron que las bibliotecas sí cuentan con personal capacitado para atender a los usuarios infantiles, y entre las razones que dieron para considerarlo así mencionaron que estos tienen la afabilidad, el gusto por el trabajo con los niños y la experiencia que se requieren para atender adecuadamente a este tipo de usuarios, además de haber recibido los cursos impartidos por la DGB de la SEP para tal fin. No obstante, durante la realización de las entrevistas la observación directa nos permitió constatar que en muy pocas bibliotecas el personal posee las cualidades descritas anteriormente, por lo cual consideramos que el porcentaje de las que cuentan con personal capacitado para atender a usuarios infantiles es en realidad menor.

Otra observación que apoya lo anterior es que durante nuestra visita a las bibliotecas notamos, en general, poca afluencia de usuarios infantiles, lo cual no está en correlación con las cualidades que los bibliotecarios mencionaron de su personal. Sería de esperar que un personal con tan buenas características tuviera capacidad para mantener un buen nivel de asistencia de usuarios, pero en la práctica no ocurre así.

Es importante aclarar que a los bibliotecarios no se les preguntó directamente respecto al nivel de estudios del personal que atiende a los usuarios infantiles, porque consideramos que un grado académico, si bien es un factor coadyuvante, no es determinante para brindar servicios adecuados a los niños.

Scire. $13: 1$ (en.-jun. 2007) 87-119. ISSN 1135-3716. 


\subsubsection{Evaluación que los bibliotecarios hacen de las actividades y los recursos de las bibliotecas públicas (motivadores)}

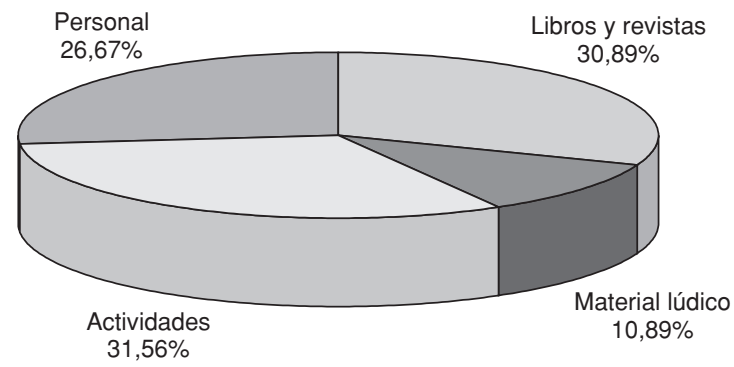

Figura 8. Evaluación que los bibliotecarios hacen de las actividades y los recursos de las bibliotecas públicas (motivadores).

Como muestran las cifras de la gráfica de la figura 8 , el mayor porcentaje de los bibliotecarios consideraron que el aspecto de su biblioteca que resultaba más motivador para los usuarios infantiles eran las actividades que realizaban. Cabe destacar que durante nuestra visita a las bibliotecas casi nunca observamos la realización de actividades para niños. Esto indica que la mayoría de las bibliotecas desarrollan este tipo de actividades de forma muy esporádica y generalmente solo durante las vacaciones de verano. Por esta razón consideramos que, si bien las actividades que se llevan a cabo resultan motivadoras para los usuarios, no son lo suficientemente regulares como para constituir un factor que logre una mayor asistencia de los niños a las bibliotecas públicas.

Después de las actividades, el aspecto de la biblioteca que los empleados consideraron más motivador para los usuarios fueron los libros y las revistas. En este punto estamos de acuerdo con los bibliotecarios, pues los libros son el recurso más utilizado por los niños. Ya que la observación directa nos permitió constatar que la principal actividad que los niños realizan en las bibliotecas son las tareas escolares. Sin embargo, consideramos que los acervos no siempre responden a las necesidades de información y esparcimiento de los usuarios infantiles. Las categorías con un menor porcentaje son "Personal" y "Material lúdico".

\subsubsection{Evaluación que los bibliotecarios hacen de las actividades y los recursos de las bibliotecas públicas (desmotivadores)}

De acuerdo con las cifras obtenidas en la gráfica de la figura 9 , encontramos que el aspecto que los bibliotecarios consideraron más desmotivador es la falta o la baja calidad del material lúdico, situación que corroboramos durante nuestras visitas, ya que, por una parte, los bibliotecarios afirmaron que hace tiempo la DGB 


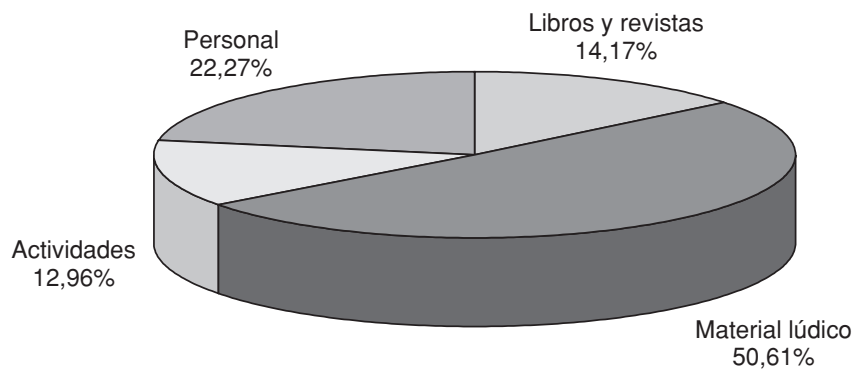

Figura 9. Evaluación que los bibliotecarios hacen de las actividades y los recursos de las bibliotecas públicas (desmotivadores).

de la SEP suspendió el envío de este tipo de material y ellos no cuentan con los recursos necesarios para adquirirlo, y, por otra, el poco material lúdico existente es insuficiente y se encuentra en muy malas condiciones, por lo que ya no resulta atractivo para los niños.

El segundo aspecto entre los más desmotivadores es el propio personal de las bibliotecas, situación que resulta contradictoria con las respuestas mostradas en la figura 7, pues la mayoría de los bibliotecarios afirmaron contar con personal adecuado para atender a usuarios infantiles. Sin embargo, y de acuerdo con la observación realizada, nos inclinamos por las cifras obtenidas en la gráfica de la figura 9, ya que una buena parte de los empleados requieren una mayor disponibilidad y creatividad para trabajar con los niños. Las categorías con un menor porcentaje fueron "Libros y revistas" y "Actividades".

\subsubsection{Medios de difusión de las bibliotecas públicas}

Como puede observarse en la gráfica de la figura 10, las categorías con mayor porcentaje son las de "Carteles en colonias y en escuelas", lo cual indica que estos son en general el medio de difusión más utilizado por las bibliotecas, pues estas instituciones optan por medios de difusión que sean, sobre todo, poco costosos, y que a la vez hagan llegar información a la mayor cantidad posible de personas. En este sentido, los carteles son un recurso que cumple con ambas expectativas y podría atraer a un mayor número de usuarios a las bibliotecas si se utilizara de manera intensiva y abarcando un área geográfica más grande. No obstante lo anterior, la observación directa nos permitió constatar que en la realidad son menos las bibliotecas que utilizan este medio, ya que durante la realización de las entrevistas muy pocas veces encontramos carteles en las escuelas, y menos aún en las colonias. Las otras categorías de esta gráfica son "Volantes", "Ninguno", "Radio" y "Televisión".

Cabe destacar que consideramos que estos medios deberían ser aprovechados en mayor medida por la DGB de la SEP, ya que su alcance y su penetración en la

Scire. $13: 1$ (en.-jun. 2007) 87-119. ISSN 1135-3716. 


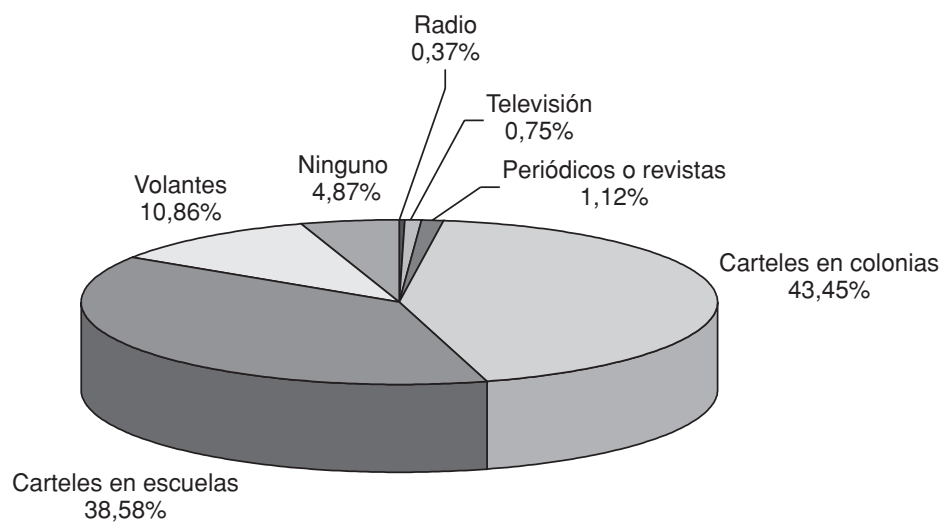

Figura 10. Medios de difusión de las bibliotecas públicas.

población infantil asegurarían que un mayor número de niños conociera la existencia de las bibliotecas públicas, así como los materiales y actividades que ofrecen.

\subsubsection{Colaboración de las bibliotecas públicas con la comunidad}

Las cifras de la figura 11 muestran un gran porcentaje de bibliotecas que no tienen ningún tipo de colaboración con la comunidad, lo que prueba el carácter de biblioteca escolar que la misma biblioteca pública ha adquirido por su trabajo, ya que encamina el mayor de sus esfuerzos al ámbito escolar, dejando de lado todos los demás.

Esta situación es preocupante, ya que toda la comunidad, incluidos los padres, son un factor que influye en la actitud de los niños hacia las bibliotecas, por lo que la biblioteca pública debería trabajar de manera conjunta con todos los estratos de la población para lograr que todos tengan una actitud positiva hacia ella.

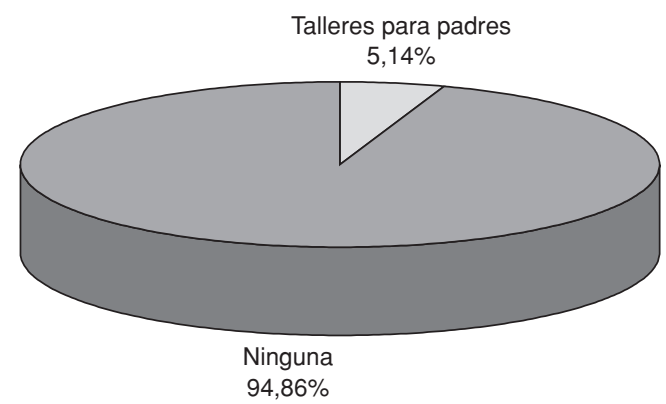

Figura 11. Colaboración de las bibliotecas públicas con la comunidad. 
Lo anterior indica que en su mayoría los bibliotecarios no son sensibles a las necesidades de su comunidad y no tienen la iniciativa necesaria para implementar actividades que motiven la asistencia de los usuarios a sus bibliotecas.

Por lo que respecta a la colaboración de las bibliotecas públicas con la comunidad, las cifras nos indican que la única actividad que los bibliotecarios desarrollan son "Talleres para padres de familia", y si se observa la cantidad de bibliotecas que los llevan a cabo puede notarse que en realidad esta categoría no es representativa. Aunque esta actividad no sea propiamente de motivación para los niños, sí funciona de manera indirecta, ya que los bibliotecarios mencionaron que, al asistir los padres de familia a los talleres con sus hijos, en ese momento podían invitar a los niños a realizar alguna actividad para distraerse.

\subsubsection{Aspectos que los bibliotecarios modificarían para mejorar la labor de motivación realizada en sus bibliotecas}

La categoría que presenta un mayor porcentaje es la de "Talleres". Los bibliotecarios que los mencionaron hicieron referencia tanto a la implantación de este tipo de actividades en sus bibliotecas como al mejoramiento de las ya existentes. Con respecto a este punto, los bibliotecarios afirmaron que los talleres están entre las actividades más atrayentes para los niños y entre las que más motivan su asistencia a las bibliotecas, por lo que resulta lógico que un buen número de bibliotecarios desee mejorar este aspecto.

También cabe destacar que durante las entrevistas no se observó nunca la realización de talleres, lo que nos hace suponer que existe una carencia en la mayor parte de las bibliotecas, o por lo menos que esta actividad no se lleva a cabo con regularidad.

La siguiente categoría en orden descendente es la de "Material lúdico". Al igual que la anterior, constituye uno de los recursos que, según los bibliotecarios, más

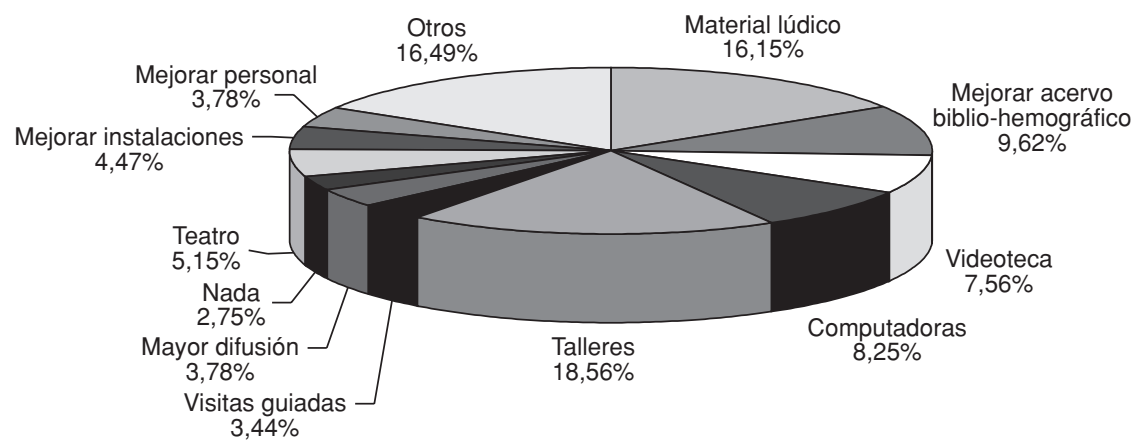

Figura 12. Aspectos que los bibliotecarios modificarían para mejorar la labor de motivación realizada en sus bibliotecas.

Scire. $13: 1$ (en.-jun. 2007) 87-119. ISSN 1135-3716. 
motivan a los niños, pero su escasez es aún mayor que la de los talleres, por lo que la adquisición de este material debería ser una prioridad en todas las bibliotecas.

Dentro de la siguiente categoría, y bajo el nombre de "Otros", tenemos los aspectos que fueron menos mencionados por los bibliotecarios, tales como la adquisición de fotocopiadora, mayor colaboración con los padres de familia, paseos y cursos de inglés, computación y guitarra. Es interesante mencionar que algunos de estos rubros son un reflejo de las necesidades propias que cada bibliotecario ha detectado en su comunidad, pero también encontramos algunas que deberían ser una preocupación esencial de toda biblioteca pública, como es la de buscar una mayor colaboración con los padres de familia. Las otras categorías de esta gráfica son "Mejorar acervo biblio-hemerográfico", "Videoteca", "Computadoras", "Teatro", "Mejorar instalaciones", "Mejorar personal", "Mejorar difusión", "Visitas guiadas" y "Nada".

\subsection{Población infantil}

\subsubsection{Edad}

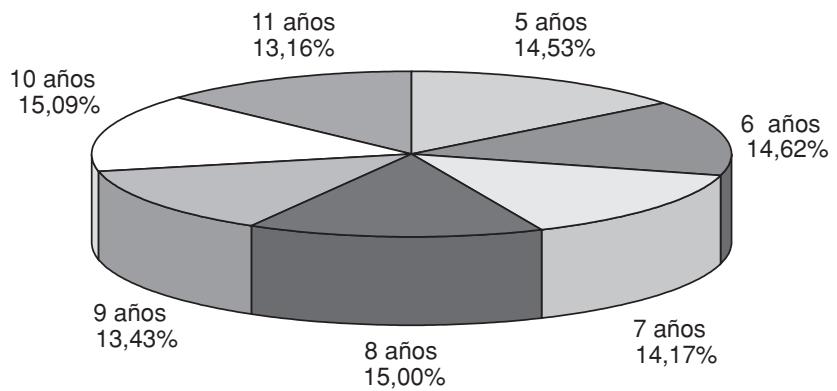

Figura 13. Edad.

La gráfica de la figura 13 muestra el porcentaje correspondiente a cada edad, el cual se había determinado previamente en el cálculo de la muestra, de forma proporcional a la población existente en cada delegación.

El objetivo era que en el estudio pudiesen estar representadas equitativa y proporcionalmente todas las edades. Cabe aclarar que, si bien el objetivo del presente trabajo no es ahondar en las diferencias que presentan las respuestas de los niños según su edad, este factor es considerado en cada una de las gráficas siguientes para hacer más precisa la presentación de los datos.

\subsubsection{Asistencia a las bibliotecas públicas}

Como puede observarse en la figura 14, la categoría con un mayor porcentaje es la que corresponde al "Sî́, lo cual parece indicar que casi todos los niños han 


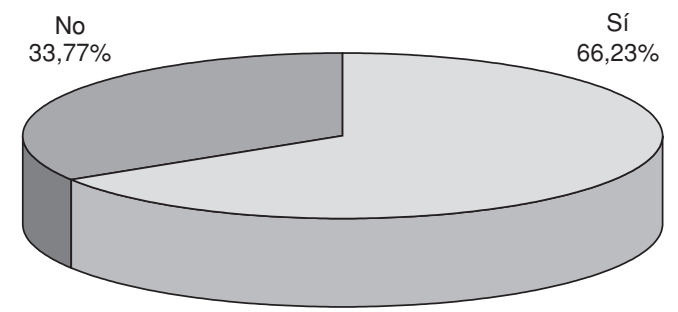

Figura 14. Asistencia a las bibliotecas públicas.

acudido alguna vez a la biblioteca pública o que asisten regularmente; sin embargo, la observación realizada nos permitió constatar que la asistencia a la mayoría de las bibliotecas es escasa. Este resultado podría deberse a que una gran cantidad de niños sí ha ido alguna vez a la biblioteca, pero solamente regresa a ella en caso de requerir alguna información, y no porque realmente esté motivado a asistir.

\subsubsection{Razones de asistencia a las bibliotecas públicas}

Las cifras de la figura 15 nos indican que la categoría con el mayor porcentaje es la de "Actividades escolares", lo cual significa que la mayoría de los niños que asisten a las bibliotecas lo hacen por mandato de profesores y/o necesidad de información para sus tareas escolares, y no porque haya algo en ellas que les guste o les llame la atención. Esto nos muestra también el carácter de biblioteca escolar que los propios niños le han adjudicado a la biblioteca pública. En este sentido podemos decir que es positivo que encuentren en la biblioteca pública un espacio de apoyo para complementar su aprendizaje escolar; sin embargo, es preocupante que no asistan a las bibliotecas por interés propio, lo cual puede ser un indicador de que las bibliotecas no han logrado implantar actividades y servicios que sean atractivos para motivar la asistencia de los niños por gusto o placer.

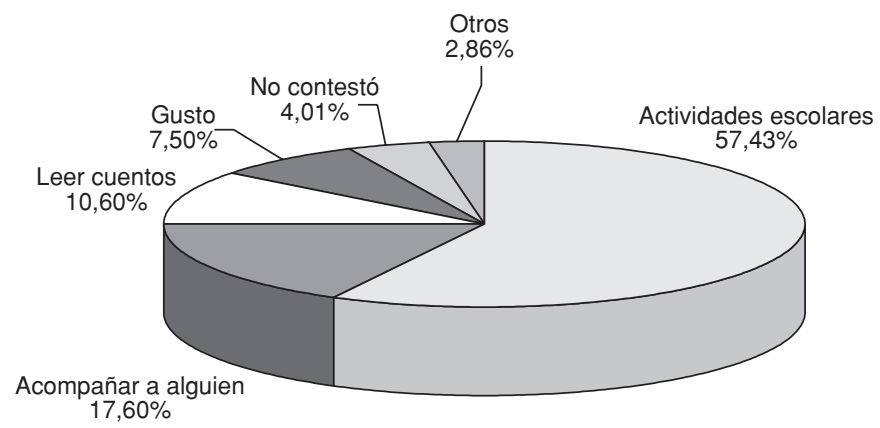

Figura 15. Razones de asistencia a las bibliotecas públicas.

Scire. $13: 1$ (en.-jun. 2007) 87-119. ISSN 1135-3716. 
Otras categorías, que presentan un menor porcentaje, son "Acompañar a alguien", "Lectura de cuentos", "Gusto", "No contestó" y "Otros".

\subsubsection{Razones de inasistencia a la biblioteca pública}

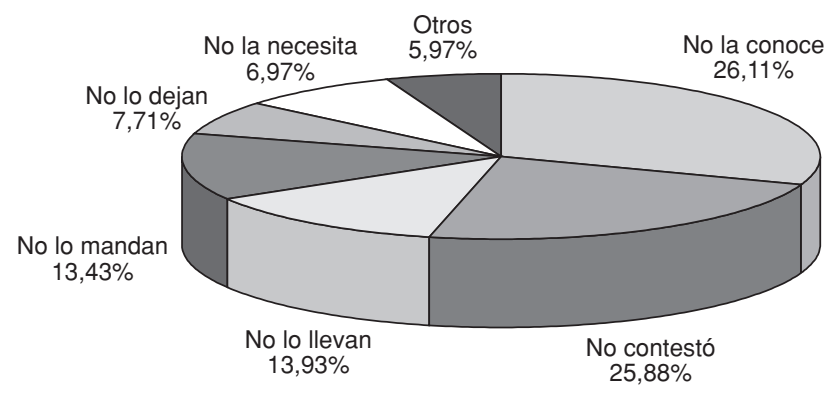

Figura 16. Razones de inasistencia a la biblioteca pública.

Como muestra la gráfica de la figura 16 , de las razones que los niños mencionaron para no haber asistido nunca a una biblioteca pública la que tiene un mayor porcentaje es que no la conocen. Esto nos deja ver que los niños necesitan tener alguna información previa que los oriente o los motive para asistir a las bibliotecas. Podemos decir, entonces, que el desconocimiento de las bibliotecas y sus servicios es el factor principal que provoca la inasistencia de los niños a ellas.

Esta situación es preocupante, ya que significa que la difusión realizada por las bibliotecas es insuficiente y poco atractiva para llamar la atención de los niños. Además demuestra el poco interés que los padres de familia y los maestros tienen en dar a conocer las bibliotecas a los niños y tratar de acercarlos a ellas.

Ante tal panorama es claro que las bibliotecas públicas necesitan realizar una gran labor de difusión para motivar la asistencia de los niños a ellas, y esta labor tendría mejores resultados si se realizara conjuntamente con los maestros de los niveles de preescolar y primaria, y con los padres de familia. Otras categorías son "No contestó", "No lo llevan", "No lo mandan", "No lo dejan", "No la necesita" y "Otros".

\subsubsection{Actividades observadas por los niños en las bibliotecas públicas}

Como muestran las cifras de la figura 17, la lectura de cuentos fue la actividad que los niños afirmaron haber visto más en las bibliotecas públicas. Sin embargo, lo observado durante nuestras visitas nos permite afirmar que lo que más se hace en las bibliotecas públicas no es leer cuentos, sino realizar las tareas escolares. Además, si se observa la gráfica de la figura 15, se notará que esta es la principal razón de asistencia de los niños a las bibliotecas. Una explicación de los

Scire. $13: 1$ (en.-jun. 2007) 87-119. ISSN 1135-3716. 


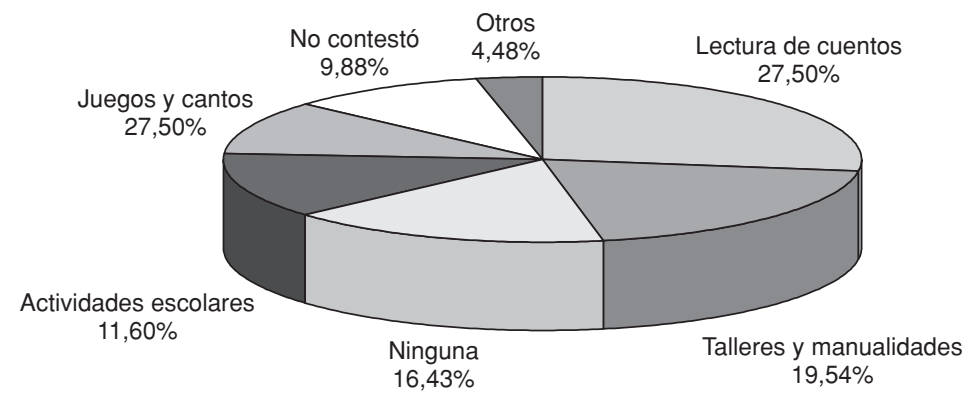

Figura 17. Actividades observadas por los niños en las bibliotecas públicas.

resultados de esta categoría podría ser que durante las entrevistas, ante la indecisión de los niños, se les mencionaron varias alternativas de respuesta entre las que estaba la hora del cuento, y ellos, aunque no la hubieran visto, asociaron subjetivamente las bibliotecas con esta actividad y respondieron afirmativamente. Otro aspecto observado en relación con la hora del cuento es que en la mayoría de las bibliotecas se lleva a cabo de forma muy esporádica, y la calidad en la realización de esta actividad suele dejar mucho que desear, por lo que resulta poco motivadora para los niños.

Otras categorías fueron "Talleres y manualidades", "Ninguna”, "Juegos y cantos" y "No contestó".

\subsubsection{Recursos documentales y materiales observados} por los niños en las bibliotecas públicas

La gráfica de la figura 18 nos indica que más de la mitad de los niños encuestados mencionó haber visto libros para niños en las bibliotecas públicas.

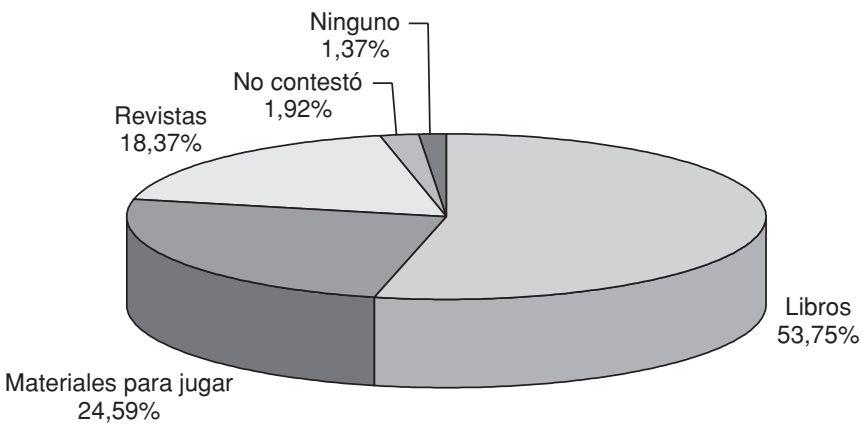

Figura 18. Recursos documentales y materiales observados por los niños en las bibliotecas públicas. 
Consideramos que esto se debe a que este material sigue siendo el recurso documental predominante en las bibliotecas públicas y el de más fácil acceso para los niños. Lo anterior es lógico si consideramos que en general el nivel de las necesidades de los niños es básico, por lo que los libros son la fuente de información que más consultan.

Otras categorías fueron "Materiales para jugar", "Revistas", "No contestó” y "Ninguna".

\subsubsection{Participación de los bibliotecarios en actividades infantiles}

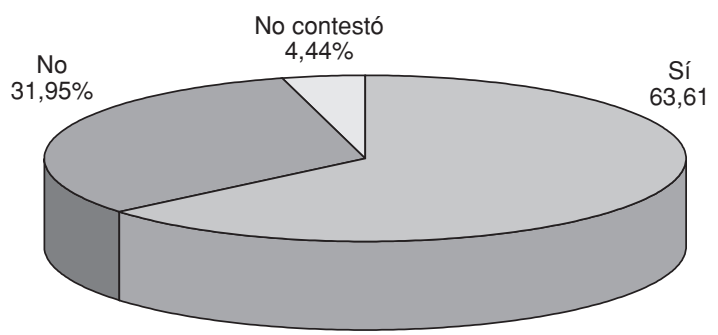

Figura 19. Participación de los bibliotecarios en actividades infantiles.

La figura 19 nos muestra que más de la mitad de los niños encuestados mencionaron haber visto a los empleados participando en juegos $\mathrm{u}$ otras actividades para usuarios infantiles, lo cual indica que la impresión que tienen los niños es de unos empleados activos y participativos. Sin embargo, nos inclinamos a pensar que dichas actividades tienen que ver más con el apoyo que brindan los bibliotecarios en la consulta y búsqueda de información que con actividades recreativas, ya que por una parte un gran porcentaje de niños va a la biblioteca a realizar tareas escolares y, por otra, en la biblioteca existen actividades recreativas solo esporádicamente. Por ello, los bibliotecarios suelen llevar a cabo actividades que tienen que ver con el apoyo en la búsqueda de información, y no con actividades recreativas y/o lúdicas.

\subsubsection{Evaluación de las actividades}

y los recursos de las bibliotecas públicas (motivadores)

Antes de comenzar con el análisis de esta gráfica es conveniente puntualizar que consideramos como motivadoras todas aquellas categorías que reflejan el agrado o satisfacción de los niños por algún aspecto de la biblioteca.

La primera categoría de la gráfica la constituyen los libros y revistas, lo que significaría que este aspecto es el que más motiva la asistencia de los niños a las bibliotecas; sin embargo, pensamos que, más que motivador, este tipo de material 


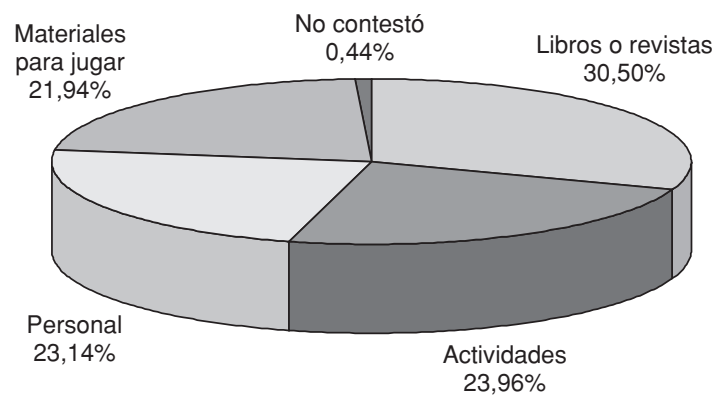

Figura 20. Evaluación de las actividades y los recursos de las bibliotecas públicas (motivadoras).

es necesario para los niños y, aunque en muchas ocasiones no llena totalmente sus requerimientos, sigue siendo el material más conocido y utilizado por ellos.

Las siguientes categorías, con un menor porcentaje, son "Actividades", "Personal", "Materiales para jugar" y "No contestó".

\subsubsection{Evaluación de las actividades}

y los recursos de las bibliotecas públicas (desmotivadores)

Como puede apreciarse en la gráfica de la figura 21, los niños entrevistados consideraron que los materiales para jugar son el aspecto más desmotivador de las bibliotecas públicas.

Es importante mencionar que durante nuestra visita a las bibliotecas pudimos constatar que los materiales para jugar constituyen, efectivamente, la colección más insuficiente, e incluso llega a ser prácticamente inexistente en algunas bibliotecas.

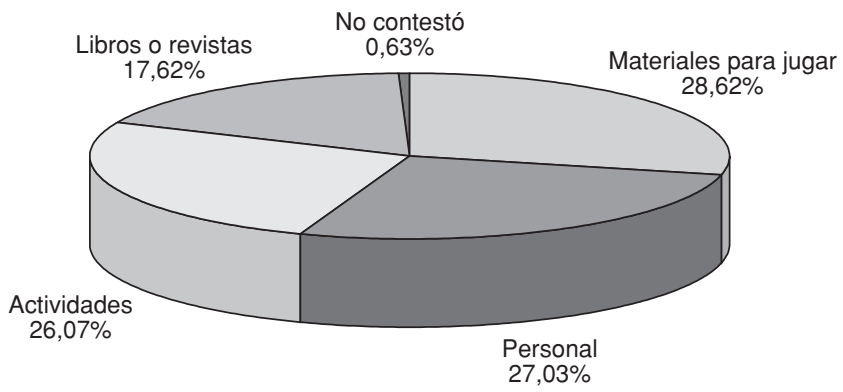

Figura 21. Evaluación de las actividades y los recursos de las bibliotecas públicas (desmotivadores).

Scire. $13: 1$ (en.-jun. 2007) 87-119. ISSN 1135-3716. 
Lo anterior es muestra de que la mayoría de las bibliotecas públicas son concebidas por usuarios y bibliotecarios como lugares cuya única función es la del estudio, y se ha dejado de lado la función de esparcimiento que estos lugares también deben cumplir.

En la medida en que las bibliotecas no cuentan con colecciones de materiales lúdicos se está desaprovechando la capacidad de juego de los niños, una herramienta que facilitaría mucho la formación de los usuarios infantiles y su motivación para lograr su asistencia a las bibliotecas.

Otras categorías fueron "El personal”, "Las actividades infantiles", "Libros y revistas" y "No contestó".

\subsubsection{Medios de difusión de las bibliotecas públicas}

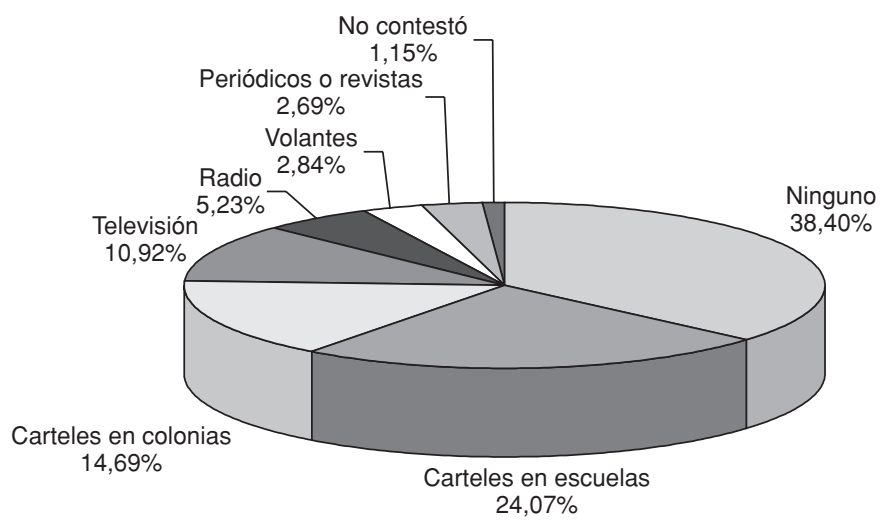

Figura 22. Medios de difusión de las bibliotecas públicas.

El primer lugar de la gráfica de la figura 22 lo ocupa la categoría "Ninguno". El porcentaje obtenido por esta nos muestra que algo más de la tercera parte de los niños no ha observado ningún tipo de difusión de las bibliotecas, lo cual podría deberse principalmente a dos razones: $a$ ) la poca labor de difusión que realizan la mayoría de las bibliotecas; $b$ ) lo poco atractivos que resultan para los niños los medios utilizados.

Otras categorías son "Carteles en escuelas", "Carteles en colonias", "Televisión", "Radio", "Volantes", "Periódicos y revistas" y "No contestó".

\subsubsection{Peticiones de los niños para motivar su asistencia a las bibliotecas públicas}

Como muestran los porcentajes de la figura 23 , al preguntar a los niños sobre lo que les gustaría que hubiera en las bibliotecas públicas para que asistieran más a ellas, la categoría que más respuestas obtuvo fue "Juegos". Esto nos indica lo im- 


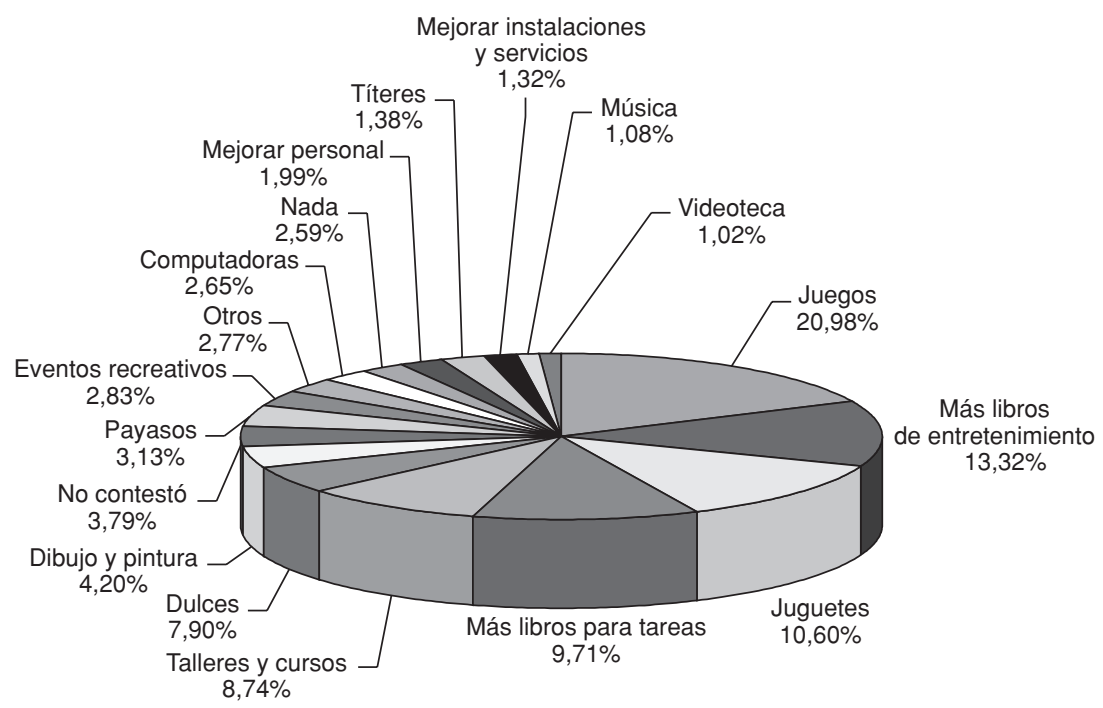

Figura 23. Peticiones de los niños para motivar su asistencia a las bibliotecas públicas.

portante que resulta para los niños el juego como motivador. Lamentablemente, la observación directa nos permitió constatar que los juegos no se encuentran entre las principales actividades que realizan las bibliotecas, lo cual se corrobora con la respuesta de los niños que se muestra en la gráfica de la figura 17, donde los juegos y cantos ocupan el lugar número 5 entre las actividades observadas en las bibliotecas.

Después de los juegos, "Más libros de entretenimiento" constituyeron el aspecto más solicitado por los niños en las bibliotecas. Esto puede deberse a que la mayoría de las bibliotecas públicas realizan la función de bibliotecas escolares y, por tanto, el mayor porcentaje de sus acervos está conformado por libros de texto.

En tercer lugar, otra petición de los niños fue la existencia de juguetes en las bibliotecas públicas. A este respecto podemos decir algo similar a lo expresado acerca de los juegos, ya que los juguetes constituyen un medio de aprendizaje muy importante para los niños. Consideramos incluso que esta categoría debería tener un porcentaje mayor de respuestas; sin embargo, muchos niños no están acostumbrados a ver juguetes en las bibliotecas, y por lo tanto no los consideraron en su respuesta.

Después de los juguetes, lo más solicitado por los niños fue "Más libros para tareas". Esto refleja la carencia de bibliotecas escolares y la insuficiencia de las bibliotecas públicas como sustitutas de estas. Durante nuestra visita a las bibliotecas observamos que la mayoría de los libros están desactualizados, de modo que los Scire. $13: 1$ (en.-jun. 2007) 87-119. ISSN 1135-3716. 
usuarios sienten la necesidad de más materiales que los ayuden a la realización de sus tareas escolares.

"Talleres y cursos" son la siguiente petición de los niños para las bibliotecas públicas. Al respecto podemos decir que la mayoría de las bibliotecas realizan este tipo de actividades, ya que la DGB de la SEP las contempla en su programa; sin embargo, en la mayoría de los casos dichas actividades se realizan de manera muy esporádica y no con la regularidad que a los usuarios infantiles les gustaría.

La categoría "Dulces", que es la siguiente en porcentaje, además de reflejar las preferencias alimenticias de los niños, también indica la asociación que estos desearían encontrar entre la biblioteca y un aspecto que les agrada mucho. El resto de categorías son "El dibujo y la pintura", "No contestó", "Payasos" y "Eventos recreativos", "Computadoras", "Nada", "Mejorar personal”, "Títeres", "Mejorar instalaciones y servicios", "Música" y "Videoteca".

3.2.12. Disposición para participar en las actividades de las bibliotecas públicas

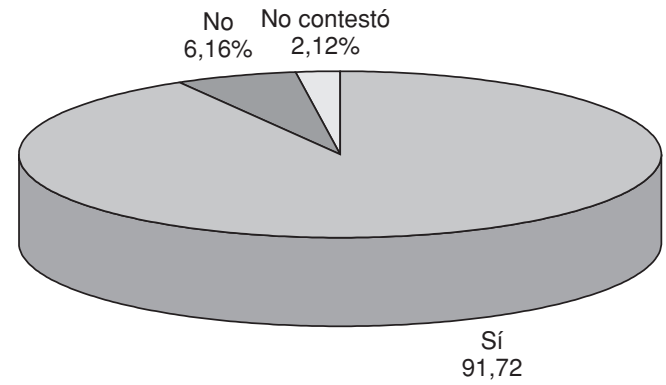

Figura 24. Disposición para participar en las actividades de las bibliotecas públicas.

Como se puede observar en la gráfica de la figura 24, la categoría con más alto porcentaje es "Sî", lo cual significa que la mayor parte de la población infantil está dispuesta a participar en las actividades que se realicen en las bibliotecas. Una explicación a esta disposición podría ser que a los niños generalmente les gusta participar en actividades prácticas, manuales y recreativas, que les permiten descargar energías y ejercitar su creatividad y su imaginación.

\section{Conclusiones}

Exponemos a continuación las principales conclusiones que se extrajeron al término del diagnóstico.

En la mayor parte de las bibliotecas públicas de la Ciudad de México no se realiza una labor de motivación propiamente dicha encaminada a lograr la asistencia 
de la población infantil a ellas, y, cuando se realiza, se lleva a cabo de una manera inadecuada.

La falta de esta labor de motivación es una de las principales razones de la baja afluencia de usuarios que registran la mayor parte de las bibliotecas públicas dentro de la Ciudad de México.

La carencia de personal capacitado, las instalaciones inadecuadas y la falta de material documental para niños son otros factores determinantes de la apatía de estos niños para asistir a las bibliotecas públicas.

Aunque existe un gran porcentaje de niños que afirman haber asistido a alguna biblioteca pública, la principal razón que mencionan para ello son las actividades escolares (mandato del profesor, realizar tareas, hacer trabajos en equipo, etcétera), lo cual refleja el carácter obligatorio de esta asistencia y la falta de visión de la biblioteca pública como lugar de esparcimiento.

\section{Recomendaciones}

De este diagnóstico se desprenden muchas recomendaciones, y se refieren en general a un mejoramiento de toda la Red Nacional de Bibliotecas Públicas en cuanto a organización, administración y control de todas las bibliotecas pertenecientes a ella. Sin embargo, consideramos que la más importante es la referente a la elaboración de un programa de motivación infantil que cuente con la participación de bibliotecarios, profesores y psicólogos infantiles. También es muy importante que se tomen en cuenta las propias peticiones de los niños, pues, aunque algunas de las cosas que ellos solicitan pueden parecer totalmente ajenas a las bibliotecas, es necesario considerar todas las sugerencias posibles y no encasillarnos en la idea de una institución seria y rígida, que finalmente no está respondiendo a las necesidades reales de una población tan importante como lo es la infantil. Al realizar y aplicar este programa será posible erradicar la idea de la biblioteca como un lugar aburrido y exclusivamente de estudio, y además se logrará que los niños se acerquen a ella por gusto e interés.

\section{Referencias}

The ALA glossary of library and information science (1983). Chicago: ALA, 1983.

Anderson, J. (1955). Manual de psicología del niño. Barcelona: Francisco Seix, 1955.

Biehler, R.; Srowman, J. (1990). Psicología aplicada a la enseñanza. México: Grupo Noriega, 1990.

Bruno, F. (1986). Diccionario de términos psicológicos fundamentales. Barcelona: Paidós, 1986.

Buonocore, D. (1976). Diccionario de bibliotecología: términos relativos a la bibliología, bibliografía, bibliofilia, biblioteconomía, archivología, documentología, tipografía y materias afines. Buenos Aires: Marimar, 1976. 2. ${ }^{\mathrm{a}}$ ed.

Scire. $13: 1$ (en.-jun. 2007) 87-119. ISSN 1135-3716. 
Busha, C. (1990). Métodos de investigación en bibliotecología: técnicas e interpretación. México: UNAM, 1990.

Consejo Nacional para la Cultura y las Artes (México). Dirección General de Bibliotecas (199-). Directorio. México: Conaculta, 199-.

Consejo Nacional para la Cultura y las Artes (México) (2001). Programa Nacional de Cultura 2001-2006: programa de fomento de la lectura y el libro Hacia un país de lectores, Publicaciones, Bibliotecas, Librerías, Educal, programa cultural Tierra Adentro. México: Conaculta, 2001.

Diccionario de ciencias de la conducta (1984). México: Trillas, 1984.

Diccionario de ciencias de la educación (1983). Madrid: Santillana, 1983.

Encuesta delegacional: Reprueban en seguridad pública (2002). // Reforma. (7 de septiembre de 2002) 1B-2B.

Fichero de actividades de fomento a la lectura en las bibliotecas públicas (2002). México: Conaculta, 2002.

Garza, G. (1975). La biblioteca como agente de cambio social y cultural. Tesis. México: el autor, 1975.

Geografía general y atlas de México (1993). México: Patria, 1993.

Glosario ALA de bibliotecología y ciencias de la información (1988). Madrid: Díaz de Santos, 1988.

Grieger, P. (1990). Animar la comunidad escolar: vivir y construir juntos. Madrid: Narcea, 1990.

Harrod, L. (1990). Harrod's librarians' glossary of terms used in librarianship, documentation and the book crafts and reference book. Aldershot: Grower, 1990. 7. ${ }^{\mathrm{a}}$ ed.

Iguiniz, J. (1959). Léxico bibliográfico. México: Biblioteca Nacional, 1959.

Indicadores para bibliotecas públicas (1984). México: SEP, 1984.

Instituto Nacional de Estadística, Geografía e Informática (México) (1991). XI censo general de población 1990: Distrito Federal: resultados definitivos. México: INEGI, 1991.

International encyclopedia of information and library science (1997). Londres: Routledge, 1997.

Jackson, B. (1981). Cada niño, una excepción: cómo motivar las aptitudes infantiles. Madrid: Morata, 1981.

Ley general de bibliotecas. // Diario Oficial de la Federación. (21 de enero de 1988) 14-17.

McTeer, W. (1979). El ámbito de la motivación: ambiental, fisiológico, mental, social. México: Manual Moderno, 1979.

Magaloni, A. (1984). Los hábitos de lectura de los estratos medios del Distrito Federal. // En XV Jornadas Mexicanas de Biblioteconomía: Memorias. México: AMBAC, 1984. 200-206.

Manifiesto de la Unesco de la biblioteca pública (1995). // Biblios. 1:2 (1995) 11.

Manifiesto de la Unesco sobre la biblioteca pública (1975). // Boletín de la Unesco. 26:3 (may.-jun. 1975) 134-135.

Marco, Pilar (1996). Motivación y creatividad en la preadolescencia. Valladolid: Universidad, 1996.

Scire. $13: 1$ (en.-jun. 2007) 87-119. ISSN 1135-3716. 
Martínez de Sousa, J. (1993). Diccionario de bibliología y ciencias afines. Madrid: Fundación Germán Sánchez Ruipérez; Pirámide, 1993. 2. a ed.

Massa, B. (1971). Dizionario tecnico di biblioteconomía: italiano-spagnolo-inglese. México: Trillas, 1971.

Méndez, I. (1984). El protocolo de investigación: lineamientos para su elaboración y análisis. México: Trillas, 1984.

Mis vacaciones en la biblioteca (2002). México: Conaculta, 2002.

Morales, E. (1973). La biblioteca escolar. // Bibliotecas y Archivos. 4 (1973) 75-95.

Negrao, May Brooking (1994). Public libraries and culture in the Latin America and Caribbean context. // Libri. 44:2 (1994) 145-152.

Palacios, M. (1978). La biblioteca pública y la Unesco: glosa del Manifiesto sobre la biblioteca pública. // Ciencia Bibliotecaria. 2 (1978) 22-28.

Pedagogía y psicología infantil: el periodo escolar (1996). Madrid: Cultural, 1996.

Pinillos, J. (1975). Principios de psicología. Madrid: Alianza, 1975.

Plano mercadotécnico: Ciudad de México y área metropolitana (1998). México: Wilsa, 1998.

El Programa Nacional de Bibliotecas Públicas 1983-1988 y el Centro Bibliotecario Nacional Biblioteca Pública de México (1988). México: SEP, 1988.

La Red Nacional de Bibliotecas Públicas (1991). México: Conaculta, 1991.

Rojas, R. (1987). Guía para realizar investigaciones sociales. México: Plaza \& Janés, 1987.

Rojas, R. (1990). El proceso de investigación científica. México: Trillas, 1990. 4. a ed.

Rondal, J. (1986). Introducción a la psicología del niño. Barcelona: Herder, 1986.

Rubinstein, J. (1967). Principios de psicología general. México: Grijalbo, 1967.

Technical dictionary of library and information science: English-Spanish, Spanish-English = Diccionario técnico de bibliotecología y ciencias de la información (1993). Nueva York: Garland, 1993.

The UNESCO Public Library Manifiesto (1994). // Libri. 44:2 (1994) 171-173.

World enciclopedia of library and information services (1993). Chicago: ALA, 1993. 3. ${ }^{\mathrm{a}} \mathrm{ed}$.

\section{Anexo I. Cuestionarios}

\section{Cuestionario-entrevista para los encargados de las bibliotecas}

El presente cuestionario tiene como objetivo recabar información sobre las actividades que las bibliotecas públicas realizan para motivar a la población infantil para asistir a ellas. La información obtenida por este medio se utilizará en la elaboración de la tesis de licenciatura que lleva por nombre "La motivación de la población infantil para lograr su asistencia a las bibliotecas públicas de la Ciudad de México", la cual se desarrolla actualmente para la Facultad de Filosofía y Letras de la UNAM.

1. ¿En esta biblioteca se realiza alguna labor de motivación para lograr una mayor asistencia de la población infantil?

$\square$ Sí $\square$ No

Scire. $13: 1$ (en.-jun. 2007) 87-119. ISSN 1135-3716. 
2. (En caso de no) ¿Cuáles son las principales razones por las que en esta biblioteca no se realiza una labor de motivación?

3. (En caso de sî́) ¿Cuáles son las principales razones por las que en esta biblioteca se realiza una labor de motivación?

4. (En caso de sî́) ¿Cómo calificaría la labor de motivación que se realiza en esta biblioteca?
Buena
Regular
Mala

5. (En caso de sí) ¿Mediante qué actividades se realiza la labor de motivación?

6. ¿Con cuáles de los siguientes materiales para niños cuenta la biblioteca?
Libros y revistas
Materiales lúdicos

7. ¿Esta biblioteca cuenta con personal capacitado para atender a los usuarios infantiles?
$\square$ Sí
No
¿Por qué?

8. ¿Cuáles de los siguientes elementos de esta biblioteca considera usted que son motivadores o desmotivadores para los niños?

$\square$ Los libros o revistas

$\square$ Las actividades

$\square$ Los materiales lúdicos

Motivador

Desmotivador

9. ¿Esta biblioteca se "promueve" por alguno de los siguientes medios?
$\square$ Radio
$\square$ Televisión
Periódicos o revistas

El personal

Ninguno

$\square$ Carteles en colonias
$\square$
Volantes

10. ¿Esta biblioteca colabora en algunas actividades con las escuelas de preescolar y las primarias o con las familias de la comunidad para motivar la asistencia de los niños a la biblioteca?
$\checkmark$ Sí
No
¿Cómo?

11. ¿En caso de contar con los recursos necesarios, ¿Qué haría usted para implementar o mejorar la motivación infantil en esta biblioteca? 
Nombre de la biblioteca

Dirección

Delegación:

\section{Cuestionario-entrevista para los niños y las niñas}

Femenino

Masculino

1. ¿Cuántos años tienes?

2. ¿Alguna vez has ido a una biblioteca pública?

$\square$ Sí $\quad \square$ No

3. (En caso de sî) ¿Por qué has ido?

4. (En caso de sí) ¿Qué actividades para niños has visto que se realicen en las bibliotecas?

5. (En caso de sí) ¿Cuáles de los siguientes materiales has visto en la biblioteca?
Libros para niños
Revistas para niños
Materiales para jugar

6. (En caso de sí) ¿Cuando has ido a la biblioteca, has visto que los empleados participan con los niños en juegos o en otras actividades?

\section{Sí $\quad \square$ No}

7. (En caso de sí) ¿Qué cosas de la biblioteca te han gustado y cuáles no te han gustado?

Los libros o revistas Las actividades Los materiales para jugar El personal

8. ¿En dónde has visto que se anuncie algo sobre la biblioteca?

$\square$ Radio $\quad \square$ Televisión $\quad \square$ Periódicos o revistas

$\square$ Carteles en tu colonia $\quad \square$ Carteles en tu escuela
Volantes
Ninguno

9. ¿Alguna vez ha ido a tu escuela o a tu colonia alguien a hablaros de la biblioteca, a invitaros a ir o a llevaros a ella?
$\square$ Escuela
Hablar
Invitar
$\square$ Llevar
Ninguno
Colonia
Hablar
Invitar
Llevar
Ninguno

10. ¿Qué te gustaría que hubiera en la biblioteca para que asistieras a ella? 
11. Si la biblioteca te invitara a participar en actividades como narración de cuentos, concursos de dibujo, obras de teatro, títeres, elaboración de figuras, ¿te gustaría asistir?
$\square$ Sí
No

Cuestionario realizado en la delegación.

\section{Anexo II. Muestreo por edades y delegaciones}

\begin{tabular}{|c|c|c|c|c|}
\hline Delegación & Edad & Total de niños & Porcentaje & Muestra \\
\hline \multirow[t]{8}{*}{ Álvaro Obregón } & 5 & 12988 & $15 \%$ & 13 \\
\hline & 6 & 13063 & $15 \%$ & 13 \\
\hline & 7 & 12361 & $14 \%$ & 12 \\
\hline & 8 & 13103 & $15 \%$ & 13 \\
\hline & 9 & 12278 & $13 \%$ & 12 \\
\hline & 10 & 12994 & $15 \%$ & 13 \\
\hline & 11 & 11891 & $13 \%$ & 11 \\
\hline & Total & 88678 & $100 \%$ & 87 \\
\hline \multirow[t]{8}{*}{ Azcapotzalco } & 5 & 8027 & $14 \%$ & 8 \\
\hline & 6 & 8054 & $15 \%$ & 8 \\
\hline & 7 & 7871 & $14 \%$ & 8 \\
\hline & 8 & 8030 & $14 \%$ & 8 \\
\hline & 9 & 7569 & $14 \%$ & 7 \\
\hline & 10 & 8142 & $15 \%$ & 8 \\
\hline & 11 & 7518 & $14 \%$ & 7 \\
\hline & Total & 55211 & $100 \%$ & 54 \\
\hline \multirow[t]{8}{*}{ Benito Juárez } & 5 & 4672 & $14 \%$ & 5 \\
\hline & 6 & 4949 & $15 \%$ & 5 \\
\hline & 7 & 4705 & $14 \%$ & 5 \\
\hline & 8 & 5063 & $15 \%$ & 5 \\
\hline & 9 & 4562 & $13 \%$ & 4 \\
\hline & 10 & 4975 & $15 \%$ & 5 \\
\hline & 11 & 4657 & $14 \%$ & 4 \\
\hline & Total & 33583 & $100 \%$ & 33 \\
\hline \multirow[t]{8}{*}{ Coyoacán } & 5 & 10624 & $14 \%$ & 11 \\
\hline & 6 & 10386 & $14 \%$ & 11 \\
\hline & 7 & 10251 & $14 \%$ & 11 \\
\hline & 8 & 10824 & $15 \%$ & 11 \\
\hline & 9 & 10194 & $14 \%$ & 10 \\
\hline & 10 & 10943 & $15 \%$ & 11 \\
\hline & 11 & 10403 & $14 \%$ & 11 \\
\hline & Total & 73625 & $100 \%$ & 76 \\
\hline
\end{tabular}

Scire. $13: 1$ (en.-jun. 2007) 87-119. ISSN 1135-3716. 


\begin{tabular}{|c|c|c|c|c|}
\hline Delegación & Edad & Total de niños & Porcentaje & Muestra \\
\hline \multirow[t]{8}{*}{ Cuajimalpa de Morelos } & 5 & 3015 & $15 \%$ & 3 \\
\hline & 6 & 2953 & $15 \%$ & 3 \\
\hline & 7 & 2934 & $15 \%$ & 3 \\
\hline & 8 & 3140 & $16 \%$ & 4 \\
\hline & 9 & 2691 & $13 \%$ & 3 \\
\hline & 10 & 2915 & $14 \%$ & 3 \\
\hline & 11 & 2535 & $12 \%$ & 3 \\
\hline & Total & 20183 & $100 \%$ & 22 \\
\hline \multirow[t]{8}{*}{ Cuauhtémoc } & 5 & 8686 & $14 \%$ & 9 \\
\hline & 6 & 9028 & $15 \%$ & 10 \\
\hline & 7 & 8737 & $14 \%$ & 9 \\
\hline & 8 & 8976 & $14 \%$ & 9 \\
\hline & 9 & 8420 & $14 \%$ & 9 \\
\hline & 10 & 9066 & $15 \%$ & 10 \\
\hline & 11 & 8637 & $14 \%$ & 9 \\
\hline & Total & 61550 & $100 \%$ & 65 \\
\hline \multirow[t]{8}{*}{ Gustavo A. Madero } & 5 & 23404 & $14 \%$ & 23 \\
\hline & 6 & 23568 & $15 \%$ & 24 \\
\hline & 7 & 22571 & $14 \%$ & 23 \\
\hline & 8 & 23559 & $15 \%$ & 24 \\
\hline & 9 & 22333 & $14 \%$ & 23 \\
\hline & 10 & 23752 & $15 \%$ & 25 \\
\hline & 11 & 21865 & $13 \%$ & 21 \\
\hline & Total & 161052 & $100 \%$ & 163 \\
\hline \multirow[t]{8}{*}{ Iztacalco } & 5 & 7543 & $15 \%$ & 8 \\
\hline & 6 & 7569 & $15 \%$ & 8 \\
\hline & 7 & 7363 & $14 \%$ & 8 \\
\hline & 8 & 7577 & $15 \%$ & 8 \\
\hline & 9 & 7040 & $13 \%$ & 7 \\
\hline & 10 & 7417 & $14 \%$ & 8 \\
\hline & 11 & 7098 & $14 \%$ & 7 \\
\hline & Total & 51607 & $100 \%$ & 54 \\
\hline \multirow[t]{8}{*}{ Iztapalapa } & 5 & 36587 & $15 \%$ & 37 \\
\hline & 6 & 36031 & $14 \%$ & 35 \\
\hline & 7 & 34776 & $14 \%$ & 35 \\
\hline & 8 & 36752 & $15 \%$ & 38 \\
\hline & 9 & 34301 & $14 \%$ & 35 \\
\hline & 10 & 36754 & $15 \%$ & 38 \\
\hline & 11 & 33074 & $13 \%$ & 32 \\
\hline & Total & 248275 & $100 \%$ & 250 \\
\hline
\end{tabular}

Scire. $13: 1$ (en.-jun. 2007) 87-119. ISSN 1135-3716. 


\begin{tabular}{|c|c|c|c|c|}
\hline Delegación & Edad & Total de niños & Porcentaje & Muestra \\
\hline \multirow[t]{8}{*}{ Magdalena Contreras, La } & 5 & 4265 & $15 \%$ & 3 \\
\hline & 6 & 4054 & $14 \%$ & 3 \\
\hline & 7 & 3956 & $14 \%$ & 3 \\
\hline & 8 & 4268 & $15 \%$ & 4 \\
\hline & 9 & 3981 & $14 \%$ & 3 \\
\hline & 10 & 4199 & $15 \%$ & 3 \\
\hline & 11 & 3694 & $13 \%$ & 3 \\
\hline & Total & 28417 & $100 \%$ & 22 \\
\hline \multirow[t]{8}{*}{ Miguel Hidalgo } & 5 & 5351 & $14 \%$ & 5 \\
\hline & 6 & 5639 & $15 \%$ & 5 \\
\hline & 7 & 5351 & $14 \%$ & 5 \\
\hline & 8 & 5588 & $15 \%$ & 5 \\
\hline & 9 & 5338 & $14 \%$ & 4 \\
\hline & 10 & 5789 & $15 \%$ & 5 \\
\hline & 11 & 5208 & $13 \%$ & 4 \\
\hline & Total & 38264 & $100 \%$ & 33 \\
\hline \multirow[t]{8}{*}{ Milpa Alta } & 5 & 1878 & $15 \%$ & 2 \\
\hline & 6 & 1968 & $15 \%$ & 2 \\
\hline & 7 & 1746 & $13 \%$ & 1 \\
\hline & 8 & 1967 & $15 \%$ & 2 \\
\hline & 9 & 1814 & $14 \%$ & 1 \\
\hline & 10 & 1881 & $15 \%$ & 2 \\
\hline & 11 & 1698 & $13 \%$ & 1 \\
\hline & Total & 12952 & $100 \%$ & 11 \\
\hline \multirow[t]{8}{*}{ Tláhuac } & 5 & 5985 & $15 \%$ & 5 \\
\hline & 6 & 5839 & $15 \%$ & 5 \\
\hline & 7 & 5466 & $14 \%$ & 5 \\
\hline & 8 & 5743 & $15 \%$ & 5 \\
\hline & 9 & 5364 & $14 \%$ & 4 \\
\hline & 10 & 5704 & $14 \%$ & 5 \\
\hline & 11 & 5154 & $13 \%$ & 4 \\
\hline & Total & 39255 & $100 \%$ & 33 \\
\hline \multirow[t]{8}{*}{ Tlalpan } & 5 & 10676 & 14 & 11 \\
\hline & 6 & 10615 & 14 & 11 \\
\hline & 7 & 10325 & 14 & 11 \\
\hline & 8 & 11047 & 15 & 11 \\
\hline & 9 & 10245 & 14 & 10 \\
\hline & 10 & 10977 & 15 & 11 \\
\hline & 11 & 10120 & 14 & 11 \\
\hline & Total & 74005 & 100 & 76 \\
\hline
\end{tabular}

Scire. $13: 1$ (en.-jun. 2007) 87-119. ISSN 1135-3716. 
Asistencia de la población infantil a las bibliotecas públicas de la Ciudad de México 119

\begin{tabular}{|c|c|c|c|c|}
\hline Delegación & Edad & Total de niños & Porcentaje & Muestra \\
\hline \multirow[t]{8}{*}{ Venustiano Carranza } & 5 & 8704 & $14 \%$ & 9 \\
\hline & 6 & 8740 & $15 \%$ & 10 \\
\hline & 7 & 8419 & $14 \%$ & 9 \\
\hline & 8 & 8761 & $15 \%$ & 10 \\
\hline & 9 & 8130 & $13 \%$ & 8 \\
\hline & 10 & 8853 & $15 \%$ & 10 \\
\hline & 11 & 8743 & $14 \%$ & 9 \\
\hline & Total & 60273 & $100 \%$ & 65 \\
\hline \multirow[t]{8}{*}{ Xochimilco } & 5 & 7200 & $15 \%$ & 6 \\
\hline & 6 & 6869 & $14 \%$ & 6 \\
\hline & 7 & 6744 & $14 \%$ & 6 \\
\hline & 8 & 7195 & $15 \%$ & 6 \\
\hline & 9 & 6790 & $14 \%$ & 6 \\
\hline & 10 & 7425 & $15 \%$ & 7 \\
\hline & 11 & 6469 & $13 \%$ & 6 \\
\hline & Total & 48692 & $100 \%$ & 43 \\
\hline
\end{tabular}

Scire. $13: 1$ (en.-jun. 2007) 87-119. ISSN 1135-3716. 